\title{
Relationship between Physical Self-Concept and Social Personality Development of Adolescents Participating in Marine Sports Activities
}

\author{
Ham, Do-Woong, Han, Kyung-Seok
}

\begin{abstract}
The purpose of this study was to investigate the relationship between the physical self-concept and social personality development of adolescents participating in marine sports activities. The purpose of this study was to investigate the relationship between the physical self-concept and social personality development of adolescents participating in marine sports activities. The purpose of this study was to investigate the relationship between the physical self-concept and social personality development of adolescents participating in marine sports activities. In conclusion, it was seen that physical self-concept of adolescents participating in marine sports activities had a partial influence on the adolescent's social personality development. Conclusively, it can be seen that physical self-concept of adolescents participating in marine sports activities can positively help the development of the adolescent's social personality. As it is the case that most of the curricula and school education of Korea is focused on athletics, it is the case that an adolescent could be seen to be deprived of wide learning opportunities if the youth is prohibited or unable to live with access to being in nature. Raising the interest in marine sports for adolescents who will play the leading role in the future of marine nations, and will be a determining factor in improving the physical self-concept of youths through marine sports activities, which can also help the social personality development of the youths as they mature to adulthood. The basic data for achieving this information was provided through this study and the data from the study confirms the results.
\end{abstract}

Keywords : Marine Sports, Adolescents, Social Character, Opportunities, Self-Concept.

\section{INTRODUCTION}

$\mathrm{I}_{\mathrm{t}}$ is noted that the stage of adolescence is accompanied by rapid physical growth and development of the youths, along with specific formation of self-concept, whereby this stage of life can prompt angst and usually becomes very sensitive to curiosity and stimulation in young developing people. Therefore, the learning and experiences noted during this time can influence and effect lifelong ability and health of a youth, and ultimately becomes a crucial factor in the development of a youth's personality, nature, character and sociality. As such, despite the importance of adolescence, the current education of Korea is consistently based on top-notch instruction, not only at school, but even during leisure time and holidays. Due

Revised Manuscript Received on July 22, 2019.

Ham, Do-Woong, Hanseo University, Dept. of Marine Sports, Seosan,31962, Korea

Han, Kyung-Seok, Hanseo University, Dept. of Marine Sports, Seosan,31962, Korea to such demands placed on Korea's young people, many youth problems such as school violence, sexual problems, drug abuse and neglect are on the rise in many demographics of adolescents [1].

Sports are recognized as an effective activity to prevent adolescence delinquency, which is becoming a significant factor contributing to various social problems in noted in modern society, thus it has been politically encouraged not only in education but also throughout society that youths engage in sports and athletic activities during the adolescent years. This reasoning is important to consider because the playing of sports in terms of socialization, such as not only as a variable in affecting the internalizing of social situations, beliefs, norms, values, attitudes, psychology, and cognitive experience, etc., but also is important to consider for today's youth as athletic activities can be seen as a factor that serves by cleansing the child's accidental and unpredictable behavior, and furthermore, it can finally act to serve as a social system that brings harmonious development to growing and maturing youths, by offering the opportunity for them to have a balance of body and mind through the use of these activities [2].

Participation in play or sports with appropriate aged peers during adolescence provides the learning of rules and norms that are necessary to experience and understand while participating in our modern society, and it can help the youth to grow into an adult having the personality and character needed to get along appropriately with others in society. Especially important, the participation of youths in marine sports offer opportunities where the youths can enjoy adventure with nature play offering an important role in developing the overall confidence, sociality and personality of the adolescent [3]. However, most of the physical activities at school are mainly composed of athletic sports. Our country is surrounded by seas and the metropolitan cities in these regions are surrounded by big rivers and lakes. In addition, even Seoul has access to the Han River, whereby this region has a great environment available for anyone in the population interested in participating in marine sports to experience and enjoying regional and local marine sports activities. Despite this information, educating the students only with athletic sports can be considered to be a narrow-minded type of educational curriculum, and there will be a limit placed on the youths experiencing this educational framework to grow into a holistic human being who conserves and cherishes the natural environment.

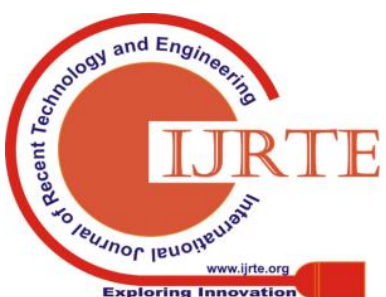


To solve the problems of adolescence and foster healthy youth, marine sports activities not only meets the adventurous and challenging needs of adolescents to commune and take part in adventures in nature, including the sporting effects of athletics, but participation in nature also allows youths to improve their intelligence by using simple and complex equipment and techniques, where especially, it will have a great impact on their improvement of collaboration and team working skills, and offer them an opportunity to continue developing socially [4].

When we lose access to be in nature near to and in our living environment, we crave the activities in nature even more, and have a sense of having lost out of natural and refreshing to the spirit experiences and adventures. Enjoying marine sports in nature can wake the sleeping human spirit and personal nature, which serves to purify and regenerate both the human body and mind, and can also enrich humanity. For this reason, the frequent participation in marine sports can expect to become a positive influence on the developmental values of youth and values for schools and communities [5]. The educational significance of marine sports education for young people who will lead the new marine era can be a large and important force in the development of our youth in Korea. By attracting young people to the open sea from the closed leisure activities such as the PC room and participating in karaoke in the city which are now rampant and popular sedentary past times, and by experiencing creative and practical leisure activities through marine sports activities, it may have a great meaning of cultivating the knowledge that can become the protagonist to develop new young leaders of future ocean countries. Therefore, in order to induce the interest of participation in the natural environment through participation in marine sports activities and to help improve individual physical fitness, personality and social development, it seems that a study is needed at this time that is focused on targeting the youth participating in marine sports activities.

Based on these necessities, the basic data for growing the adolescents into a sound and healthy body of youths utilizing the marine sports activities will be proposed through this study. The purpose of this study was to examine the relationship between the physical self-concept and the emerging social personality development in adolescents participating in marine sports activities. It also has another purpose of providing reference materials that can help with the proposed inclusion of more marine sports during the revision of the physical education curriculum at schools in Korea. To achieve this purpose, specific research hypotheses are proposed as follows. First, there is a correlation between the physical self-concept and social personality development of adolescents participating in marine sports activities. Second, there is a causal relationship between the physical self-concept and social personality development of adolescents participating in marine sports activities.

\section{RESEARCH METHODS}

\subsection{Study subjects}

The subjects of this study were youths enrolled in middle and high schools participating in marine sports activities in 2018. For the sampling, the purposive sampling method was used in this case. Of the total 200 questionnaires, the questionnaires of 9 people having missing or insincere responses were excluded, and a total of 191 copies were used as the final analysis data resources.

\subsection{Survey tool}

In this study, questionnaires were used as the primary survey tools. The questionnaire was composed of 3 questions on the general characteristics of the subjects, 22 questions on the physical self-concept as an independent variable, and 22 questions on the social personality development as a dependent variable. The measurement method for each question has used the Likert scale of 'absolutely not at all, 1 point', 'not at all, 2 points', 'normal, 3 points', 'agree, 4 points' and 'very agree, 5 points.'

\subsubsection{Physical self-concept}

For the survey tool for measuring physical self-concept, a Korean version of physical self-concept questionnaire developed by Kim [4] was used. This questionnaire was thereby validated through previous studies [5-7]. The questionnaire used in this study was modified or supplemented to suit the subject and purpose of the study. The sub-variables of physical self-concept were classified into 6 factors: athletic competence, flexibility, athletic performance, health status, exercise level, and appearance.

\subsubsection{Social personality development}

For the survey tool that was used for measuring social personality development, the youth integrated personality scale of Huh \& Park [8] and the youth sociality scale of Yoon \& Kim [9] were used. This questionnaire was also then validated through previous studies [10 13]. The questionnaire used in this study was modified or supplemented to suit the subject and purpose of the study. The sub-variables of social personality development were classified into 6 factors: manners, sociality, emotional stability, normality, character, and learning attitude.

\subsection{Validity and reliability}

In order to test the validity and reliability of the questionnaire in this study, an exploratory factor analysis and Cronbach's were conducted, and the factor rotation was performed through an orthogonal rotation method of Varimax rotation. In addition, verification of KMO and Bartlett's sphere formation was also performed simultaneously.

\subsubsection{Physical self-concept}

For physical self-concept, the Bartlett unit matrix was 2383.670 , the probability of significance was .001 , and the KMO index was .830 showing the selection of the variables was appropriate and used in this case. Based on this, 6 factors were extracted as a result, which served as the material conducting a factor analysis on 22 questions, and it was shown to explain approximately $71.741 \%$ of total variance. 
The eigenvalues for the sub-factors of the physical self-concept were athletic competence (.730 .774), flexibility (.774 .883), exercise ability (.649 .895), health status (.793 .889), exercise level (.738 .828), and appearance (.614 .813). In addition, the reliability value has shown a relatively high level of reliability with notations for athletic competence (.807), flexibility (.812), exercise ability (.810), health status (.820), exercise level (.828), and appearance (.853).

\subsubsection{Social personality development}

For social personality development, the Bartlett unit matrix was 2315.527 , the probability of significance was .001 , and the KMO index was .823 showing the selection of the variables was appropriate. Based on this, there were 6 factors which were extracted as a result conducting a factor analysis on 24 questions, and it was shown to explain approximately $66.717 \%$ of the total variance. The eigenvalues for the sub-factors of the social personality development were the manners (.606 .784), sociality (.485 .867), emotional stability (.554 .792), normality (.630 .741), character (.697 .915), and learning attitude (.593 .862). In addition, the reliability value has shown a relatively high level of reliability with the noted manners (.803), sociality (.809), emotional stability $(.811)$, normality $(.811)$, character $(.840)$, and learning attitude (.827).

\subsection{Data processing}

The data collected for the purpose of the study included a total of 191 copies of questionnaires, excluding the questionnaires which were deemed inappropriate for the study. To confirm the normal distribution, validity and reliability of the collected data, a statistical analysis, exploratory factor analysis and reliability analysis using SPSS 21.0 were conducted. Additionally, a correlation analysis was conducted in order to see the relationship between variables, and a multiple regression analysis was conducted in order to investigate the causal relationship between variables. At such time, the level of significance was $\alpha=.05$.

\section{RESSERCH RESULTS}

\subsection{Correlation analysis result}

A correlation analysis was conducted in order to investigate the relationship between physical self-concept and social personality development of adolescents participating in marine sports activities, and the results are shown in "Table 1 "'.

Table 1: The relationship between physical self-concept and social personality development

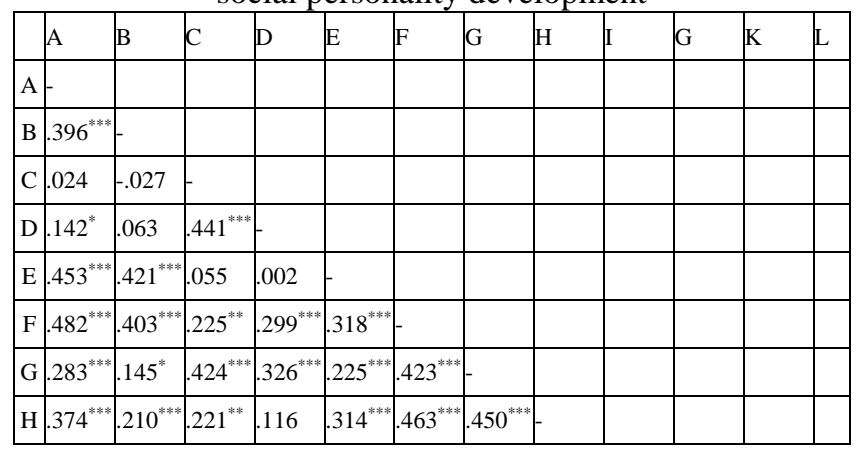

\begin{tabular}{|c|c|c|c|c|c|c|c|c|c|c|c|}
\hline I & $803^{* * * *}$ & $314^{* * *}$ & .069 & .058 & $.481^{* * *}$ & $.345^{* * * *}$ & $.264^{* * * *}$ & $436^{* * *}$ & & & \\
\hline $\mathrm{J}$ & $424^{* * *}$ & $.553^{* * *}$ & .134 & .129 & $.492^{* * *}$ & $.390^{* * *}$ & $300^{* * * *}$ & $323^{* * *}$ & $464^{* * *}$ & & \\
\hline $\mathrm{K}$ & $241^{* * * *}$ & $.215^{*}$ & $.567^{* * *}$ & $.220^{* *}$ & $.272^{* * *}$ & $.281^{* * *}$ & $412^{* * * *}$ & $358^{* * *}$ & $187^{* *}$ & $365^{* * *}$ & \\
\hline L & $257^{* * * *}$ & $\mid 259^{* * *}$ & $.344^{* * *}$ & $.276^{* * * *}$ & $\mid .170^{*}$ & $.314^{* * *}$ & $.346^{* * * *}$ & $312^{* * *}$ & $.243^{* *}$ & $.359^{* * *}$ & $.490^{* * * *}$ \\
\hline
\end{tabular}
p $<.05,{ }^{* * *} \mathrm{p}<.01,{ }^{* * * *} \mathrm{p}<.001$

A: Exercise competence. B: flexibility. C: exercise ability. D: health status. E: exercise level. F: appearance. G: manners. H: sociality. I: emotional stability. J: normality. K: character. L: learning attitude.

As shown in "Table 1", the exercise competence had a positive correlation with manners $(\mathrm{r}=.842)$, sociality $(\mathrm{r}=.540)$, emotional stability $(\mathrm{r}=.573)$, normality $(\mathrm{r}=.448)$, and learning attitude( $\mathrm{r}=.331)$. The flexibility had a positive correlation with manners $(\mathrm{r}=.546), \quad$ sociality $(\mathrm{r}=.823)$, emotional stability $(\mathrm{r}=.343)$, normality $(\mathrm{r}=.222)$, character $(\mathrm{r}=.251)$, and learning attitude $(\mathrm{r}=.197)$. The exercise ability had a positive correlation with manners $(\mathrm{r}=.627)$, sociality $(\mathrm{r}=.436)$, emotional stability $(\mathrm{r}=.691)$, normality $(\mathrm{r}=.460)$, and learning attitude $(\mathrm{r}=.335)$. The health status had a positive correlation with manners $(\mathrm{r}=.584), \quad$ sociality $(\mathrm{r}=.377)$, emotional stability $(\mathrm{r}=.510), \quad$ normality $(\mathrm{r}=.429)$, and learning attitude $(\mathrm{r}=.315)$. The exercise level had a positive correlation with manners $(\mathrm{r}=.478)$, sociality $(\mathrm{r}=.248)$, emotional stability $(\mathrm{r}=.375), \quad$ normality $(\mathrm{r}=.312), \quad$ and learning attitude $(\mathrm{r}=.158)$. The appearance had a positive correlation with character $(\mathrm{r}=.792)$.

\subsection{Relationship between physical self-concept and social personality development}

A Multiple regression analysis was conducted in order to investigate the relationship between physical self-concept and social personality development of marine leisure sports participants of adolescents participating in marine sports activities.

\subsubsection{Relationship between physical self-concept and manners}

Table 2: Relationship between physical self-concept and manners

\begin{tabular}{|l|l|l|l|l|l|l|}
\hline & $\mathrm{B}$ & SE & Beta & $t$ & tolerance & VIF \\
\hline Constant & 207 & .228 & & .909 & & \\
\hline Exercise competence & .609 & .050 & .618 & $12.204^{* * * * *}$ & .562 & 1.766 \\
\hline Flexibility & .094 & .029 & .132 & $3.216^{* * *}$ & .703 & 1.422 \\
\hline Exercise ability & 168 & .035 & .205 & $4.873^{* * * *}$ & .670 & 1.493 \\
\hline Health status & 175 & .053 & .152 & $3.330^{* * * *}$ & .570 & 1.754 \\
\hline Exercise level & -.078 & .060 & -.058 & -1.287 & .575 & 1.738 \\
\hline appearance & .020 & .023 & .030 & .843 & .945 & 1.058 \\
\hline
\end{tabular}

$\mathrm{R}^{2}=.782$, Corrected $\mathrm{R}^{2}=.775, \mathrm{~F}=110.168^{\text {*** }}$

${ }^{* *} \mathrm{p}<.01,{ }^{* * *} \mathrm{p}<.001$

As shown in "Table 2", physical self-concept had a statistically significant effect on manners $(\mathrm{F}=110.168$, $\mathrm{p}<.001)$, and the explanatory power of this variable was approximately $78.2 \%\left(\mathrm{R}^{2}=.782\right)$. When looking at the beta values as a relative influence of physical self-concept on manners, a positive influence was shown in athletic competence $(\beta=.618, p<.001)$, flexibility $(\beta=.132, p<.01)$, exercise ability $(\beta=.205, \mathrm{p}<.001)$, and health status $(\beta=.152$, p $<.001)$. 


\subsubsection{Relationship between physical self-concept and sociality}

Table 3: Relationship between physical self-concept and

\begin{tabular}{|l|l|l|l|l|l|l|}
\hline & $\mathrm{B}$ & $\mathrm{SE}$ & Beta & $t$ & tolerance & VIF \\
\hline Constant & .083 & .347 & & .240 & & \\
\hline Exercise competence & .204 & .076 & .156 & $2.689^{* *}$ & .562 & 1.766 \\
\hline Flexibility & .681 & .044 & .717 & $15.301^{* * *}$ & .703 & 1.422 \\
\hline Exercise ability & .047 & .053 & .043 & .894 & .670 & 1.493 \\
\hline Health status & 186 & .080 & 121 & $2.320^{*}$ & .570 & 1.754 \\
\hline Exercise level & -.157 & .092 & -.088 & -1.705 & .575 & 1.738 \\
\hline appearance & -.003 & .035 & -.003 & -.077 & .945 & 1.058 \\
\hline $\mathrm{R}^{2}=.716$, Corrected $\mathrm{R}^{2}=.707, \mathrm{~F}=77.248^{* * * *}$ & & & \\
\hline${ }^{*} \mathrm{p}<.05,{ }^{* *} \mathrm{p}<.01,{ }^{* * *} \mathrm{p}<.001$
\end{tabular}

As shown in "Table 3", the variable of the youth's physical self-concept had a statistically significant effect on sociality $(\mathrm{F}=77.248, \mathrm{p}<.001)$, and the explanatory power of this variable was approximately $71.6 \%\left(\mathrm{R}^{2}=.716\right)$. When looking at the beta values as a relative influence of physical self-concept on sociality, a positive influence was shown in athletic competence $(\beta=.156, p<.01)$, flexibility $(\beta=.717$, $\mathrm{p}<.001)$, and health status $(\beta=.121, \mathrm{p}<.05)$.

\subsubsection{Relationship between physical self-concept and emotional stability}

Table 4: Relationship between physical self-concept and emotional stability

\begin{tabular}{|l|l|l|l|l|l|l|}
\hline & $\mathrm{B}$ & $\mathrm{SE}$ & Beta & $t$ & tolerance & VIF \\
\hline Constant & .845 & .324 & & $2.604^{* *}$ & & \\
\hline Exercise competence & .215 & .071 & .217 & $3.032^{* *}$ & .562 & 1.766 \\
\hline Flexibility & -.019 & .042 & -.026 & -.451 & .703 & 1.422 \\
\hline Exercise ability & .427 & .049 & .516 & $8.676^{* * *}$ & .670 & 1.493 \\
\hline Health status & .248 & .075 & .213 & $3.308^{* * *}$ & .570 & 1.754 \\
\hline Exercise level & -.060 & .086 & -.045 & -.701 & .575 & 1.738 \\
\hline appearance & .018 & .033 & .028 & .557 & .945 & 1.058 \\
\hline $\mathrm{R}^{2}=.564$, Corrected $\mathrm{R}^{2}=.550, \mathrm{~F}=39.645^{* * *}$ \\
$*_{*}^{*}{ }^{* * * *}$
\end{tabular}

${ }^{* *} \mathrm{p}<.01,{ }^{* * * *} \mathrm{p}<.001$

As shown in "Table 4", physical self-concept had a statistically significant effect on the variable of emotional stability $(\mathrm{F}=39.645, \mathrm{p}<.001)$, and the explanatory power of this variable was approximately $56.4 \%\left(\mathrm{R}^{2}=.564\right)$. When looking at the beta values as a relative influence of physical self-concept on emotional stability, a positive influence was shown in athletic competence $(\beta=.217, p<.01)$, exercise ability $(\beta=.516, p<.001)$, and health status $(\beta=.213, p<.001)$.

\subsubsection{Relationship between physical self-concept and normality}

Table 5: Relationship between physical self-concept and normality

\begin{tabular}{|l|l|l|l|l|l|l|}
\hline & $\mathrm{B}$ & $\mathrm{SE}$ & Beta & $t$ & tolerance & VIF \\
\hline Constant & .891 & .459 & & 1.940 & & \\
\hline Exercise competence & .231 & .100 & .208 & $2.295^{*}$ & .562 & 1.766 \\
\hline Flexibility & -.039 & .059 & -.048 & -.657 & .703 & 1.422 \\
\hline Exercise ability & .267 & .070 & .288 & $3.835^{* * *}$ & .670 & 1.493 \\
\hline Health status & .289 & .106 & .223 & $2.730^{* * *}$ & .570 & 1.754 \\
\hline Exercise level & -.042 & .122 & -.028 & -.342 & .575 & 1.738 \\
\hline appearance & -.014 & .047 & -.019 & -.307 & .945 & 1.058 \\
\hline $\mathrm{R}^{2}=.303$, Corrected $\mathrm{R}^{2}=.280, \mathrm{~F}=13.325^{* * * *}$ \\
\hline
\end{tabular}

p $<.05,{ }^{* * *} \mathrm{p}<.01,{ }^{* * *} \mathrm{p}<.001$

As shown in "Table 5", the variable of physical self-concept had a statistically significant effect on normality $(\mathrm{F}=13.325, \mathrm{p}<.001)$, and the explanatory power of this variable was approximately $30.3 \%\left(\mathrm{R}^{2}=.303\right)$. When looking at the beta values as a relative influence of physical self-concept on normality, a positive influence was shown in

athletic competence $(\beta=.208, \quad \mathrm{p}<.05)$, exercise ability $(\beta=.288, \mathrm{p}<.001)$, and health status $(\beta=.223, \mathrm{p}<.01)$.

\subsubsection{Relationship between physical self-concept and character}

Table 6: Relationship between physical self-concept and

\begin{tabular}{|l|l|l|l|l|l|l|}
\hline \multicolumn{1}{|c|}{} & B & SE & Beta & $t$ & $\begin{array}{l}\text { tolera } \\
\text { nce }\end{array}$ & VIF \\
\hline Constant & .365 & .392 & & .930 & & \\
\hline Exercise competence & .004 & .086 & .003 & .047 & .562 & 1.766 \\
\hline Flexibility & .082 & .050 & .084 & 1.638 & .703 & 1.422 \\
\hline Exercise ability & .150 & .059 & .133 & $2.521^{*}$ & .670 & 1.493 \\
\hline Health status & .016 & .090 & .010 & .172 & .570 & 1.754 \\
\hline Exercise level & -.166 & .104 & -.091 & -1.595 & .575 & 1.738 \\
\hline appearance & .696 & .040 & .772 & $17.391^{* * *}$ & .945 & 1.058 \\
\hline $\mathrm{R}^{2}=.657$, Corrected $\mathrm{R}^{2}=.646, \mathrm{~F}=58.867^{* * * * *}$ \\
\hline
\end{tabular}
${ }^{*}<<.05,{ }^{* * * *} \mathrm{p}<.001$

As shown in "Table 6", the variable of physical self-concept had a statistically significant effect on character $(\mathrm{F}=58.867, \mathrm{p}<.001)$, and the explanatory power of this variable was approximately $65.7 \%\left(\mathrm{R}^{2}=.657\right)$. When looking at the beta values as a relative influence of physical self-concept on character, a positive influence was shown in exercise ability $(\beta=.133, \mathrm{p}<.05)$, and appearance $(\beta=.772$, $\mathrm{p}<.001)$.

\subsubsection{Relationship between physical self-concept and learning attitude}

Table 7: Relationship between physical self-concept and learning attitude

\begin{tabular}{|l|l|l|l|l|l|l|}
\hline & B & SE & Beta & $t$ & tolerance & VIF \\
\hline Constant & .784 & .620 & & 1.264 & & \\
\hline Exercise competence & .261 & .136 & .188 & 1.924 & .562 & 1.766 \\
\hline Flexibility & -.034 & .080 & -.034 & -.424 & .703 & 1.422 \\
\hline Exercise ability & 240 & .094 & .207 & $2.556^{*}$ & .670 & 1.493 \\
\hline Health status & .361 & .143 & .222 & $2.522^{*}$ & .570 & 1.754 \\
\hline Exercise level & -.243 & .164 & -.129 & -1.477 & .575 & 1.738 \\
\hline appearance & .125 & .063 & .135 & $1.973^{*}$ & .945 & 1.058 \\
\hline
\end{tabular}

$\mathrm{R}^{2}=.190$, Corrected $\mathrm{R}^{2}=.164, \mathrm{~F}=7.204^{* *+}$

p $<.05,{ }^{* * *} \mathrm{p}<.001$

As shown in "Table 7", the variable of physical self-concept had a statistically significant effect on learning attitude $(\mathrm{F}=7.204, \mathrm{p}<.001)$, and the explanatory power of this variable was approximately $19.0 \%\left(\mathrm{R}^{2}=.190\right)$. When looking at the beta values as a relative influence of physical self-concept on learning attitude, a positive influence was shown in exercise ability $(\beta=.207, p<.05))$, health status $(\beta=.222, \mathrm{p}<.05)$, and appearance $(\beta=.135, \mathrm{p}<.05)$.

\section{DISCUSSION}

The purpose of this study was to investigate the relationship between physical self-concept and social personality development in adolescents participating in marine sports activities, in order to present basic data that can help become a predicting factor to influence youths to grow sound and healthy youths in Korea through participation in marine sports activities during the emerging adolescence period. 
When discussing based on these results, it is noted that the results of the study are as follows.

Our youth undergo stressors in life due to an unstable psychological situation based on fierce competition and a rapidly changing social structure that puts pressure on adolescents to succeed in society and in their academic careers. Under these basic assumptions that marine sports can have a positive impact on their quality of life, by identifying the relationship between the physical self-concept and social personality development of adolescents in order to raise the interest on the marine sports activities, the goal of the study was to help improve the physical self-concept and develop the social personality through the participation of youths in marine sports activities. In this study which was conducted in order to achieve these objectives, the physical self-concept of adolescents participating in marine sports activities had been noted as having a partial correlation, as well as influence on the social personality development of the youths in Korea. Therefore, the physical self-concept of adolescents participating in marine sports activities had a positive influence on the social personality development of the youths in Korea. In this regard, the study showing that flexibility among physical self-concept affects the manner [14] supports this study result. A study indicating that higher flexibility among physical self-concept improves sociality [15] partially supports the results of this study in that athletic competence, flexibility, and health status have a positive impact on the sociability of adolescents. This means that athletic competence and flexibility raised through marine sports activities can be a positive effect on the manners and sociality of youths. A study which indicates participation in 12 weeks of regular exercise helps the emotional stability through the influence of image changes on the body such as exercise ability and appearance [16] supports the result of this study in that athletic competence, exercise ability, and health status influence emotional stability and normality. In a study targeting Taekwondo practitioners, the concept of physical self has claimed to have a close relationship with the advent of character development in youths [17]. Personality is a whole impression of an individual, and it is inherent in the meaning of value as exhibited by an adolescent, such as when taking in to consideration the character, tendency, individuality, and personality of the person [18]. Therefore, it can be seen that physical self-concepts such as exercise ability and appearance may have affected overall tendency and impression. Hwang [19] argued that among physical self-concept, physical activities, sports competence and appearance, etc., especially had an impact on the learning attitudes, especially on relationships that the youths had with the teacher. This is in context with the claim that among the physical self-concept of this study, exercise ability, in other words physical activity competence and appearance had a positive influence on learning attitudes. These claims are consistent with the assertion of Kang [20] that appearance and physical activities have an influence on learning attitude.

\section{CONCLUSION}

The purpose of this study was to investigate the relationship between physical self-concept and social

personality development of adolescents participating in marine sports activities. To achieve this, a survey was conducted targeting 191 adolescents participating in marine sports activities in 2018. In the study, the frequency analysis, exploratory factor analysis, reliability test, correlation analysis, and multiple regression analysis were conducted for data processing using the SPSS 21.0 statistical program. The following results were obtained.

First, as a result of examining the correlation between physical self-concept and social personality development of adolescents participating in marine sports activities, athletic competence, flexibility, exercise ability, health status, and exercise level were positively correlated with manners, sociality, emotional stability, and normality, and the appearance was positively correlated with character of the youths.

Second, athletic competence, flexibility, exercise ability, and health status had a positive influence on f-manners. Additionally, it is important to note that the athletic competence, flexibility, and health status had a positive influence on sociality, and athletic competence, exercise ability, and health status had a positive influence on emotional stability and normality. In this case, the exercise ability and appearance had a positive influence on character, and the exercise ability, health status and appearance had a positive influence on learning attitude.

In conclusion, it was seen that the physical self-concept of adolescents participating in marine sports activities had a partial influence on the youth's social personality development. Conclusively, it can be seen that the physical self-concept of adolescents participating in marine sports activities can positively help the development of the youth's social personality. As most of school education of Korea is focused on athletics, the students being educated by that curricula are being deprived of wide learning opportunities to live with nature. Raising the interest in marine sports for adolescents who will play the leading role in future of marine nations, and improving physical self-concept through marine sports activities can help the social personality development of adolescents. The basic data for achieving this was provided through this study results.

\section{ACKNOWLEDGMENT}

This study was from the 2019 Academic Research Support Project of Hanseo University.

\section{REFERENCES}

1. I.K. Park, "Effects of Exercises and Electronic Games on Self-Esteem and Aggression in Middle School Students". Journal of coaching development. 19(4), 3-14, 2017.

2. B.J. Lee, An introduction to sports sociology. Donghwa publisher; 1998

3. J.S. Lim, C.H. Yang, "Relationship between Sports Confidence and Class Satisfaction according to Adolescents' Participation in Marine Sports". Journal of the Korea Convergence Society. 6(4), 169-176, 2015.

4. B.J. Kim, "Development and Validation of the Korean Version of the Physical Self-Description Questionnaire(PSDQ)". Korean Society of Sport Psychology. 12(2), 69-90, 2001 
5. J.Y. Shim, Y.S. Yook, "The Effects of Dance Sports on Physical Profile and Self-Concept among Obese Middle Aged Women". Korean Society of Sport Psychology. 19(2), 251-271, 2008.

6. Y.H. Park, "A Study on the Effects of the Progress of physical Self-Consciousness of Ball Sports Program". Journal of coaching development. 9(2), 309-316, 2007.

7. K.S. Han, "The physical self-conception that dance-sport influences elementary school students. Korean Society of Leisure Sport". 8, 153-170, 2004.

8. S.H. Huh, S.M. Park, "A study for development of the integrated humanity scale for children". The Journal of Child Education. 24(4), 89-103, 2015

9. J.W. Yoon, E.J. Kim, "Validation study of Adolescent Sociality Scale". The Korean Psychological Association. 2006(1), 658-659, 2006.

10. M.S. Ko, E.C. Kwak, "Relationship between Sex, Sport Character, Empathy and Pro-social Behavior among Elementary School Student who experienced School Sport Club". The Korean Journal of the Elementary Physical Education. 21(3), 17-33, 2015.

11. H.I. Kwon, S.H. Woo, Y.J. Kang, "The Effect of Intensive After-school New-sports Program on Middle School Students' Personality Development". Korean Journal of physical education. 53(2), 215-226, 2014.

12. S.H. Lee, "Effects of Participation Motivation and Attitudes Toward Sports on Development of Sociability Among Middle Schoolers Participating in After-school Sports Activities". Korean Journal of physical education. 49(6), 103-113, 2010.

13. S.J. Seo, C.S. Lee, "A Study on Relationship between Participation in Dance Sports and Interpersonal Relation and Development of Sociality". Journal of Korean Society for the Study of Physical Education. 13(2), 21-42, 2008.

14. M.B. Choi, H.B. Lee, "The Relationship between Physical Self-Concept and Personality and Manners in Judo Youth”. Journal of Korean Society for Sport Anthropology. 12(2), 15-38, 2017.

15. S.S. Kim, "The effect of Taekwondo practice for the body concept and social abilities". Master, Korea national sport University, 2008.

16. K.W. Kim, "Effects of Physical Exercise on Physical Self-Concept". Korean Society of Sport psychology. 14(1), 1-12, 2003.

17. M.S. Oh, "The Effect of Elementary Student's Taekwondo Training on their Personality Education, Physical Self-concept and Adjustment to School Life". Master, Kyunghee University, 2006.

18. J. Lee, S.K. Yoo, Y.O. Lee, "Exploring Instructional Methods for the Integration of Subject Education and Character Education". The Korean Journal of Educational Methodology Studies. 26(3), 463-487, 2014

19. B.B. Hwang, "An Influence on Physical Self-Conception, Character Development and Life Attitude of Elementary School Student's Taekwondo Training". Korean Journal of Sports Science. 25(1), 221-238, 2016.

20. H.M. Kang, "The Influence of Social Ability in School Life Attitude According to Physical Self-Concept of Taekwondo Trainee". Master, Kyunghee University, 2014.

\section{AUTHORS PROFILE}

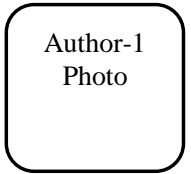

Ham, Do-Woong, Professor Dept, of Leisure marine Sports, Hanseo University, Korea.

President of Korea Sports Fishing Association.

President of Kyungkido Waterski \& wakesports Association.

Vice-chairman of Korea Sport Society.

Precident of Hanseo Univ. Marine Education Cente

\section{Author-2}

Photo
Han, Kyung-Seok, Director of Hansmarine Research Institute, Korea. 